\title{
Apontamentos sobre linguística sistêmico-funcional, contexto de situação e transitividade com exemplos de livros de literatura infantil
}

\author{
Notes on systemic functional linguistics, context of \\ situation and transitivity with examples from children's \\ picture books
}

Viviane M. HeBERLE

(Universidade Federal de Santa Catarina - Departamento de Língua e Literatura Estrangeiras/ Programa de Pós-Graduação em Inglês: Estudos Linguísticos e Literários - Florianópolis - SC - Brasil)

\section{RESUMO}

Devido à relevante contribuição da Linguística sistêmico-funcional (LSF) para estudos em Linguística Aplicada e áreas afins, inicialmente apresento considerações gerais sobre LSF, o contexto de situação e as metafunções, para então discutir o sistema de transitividade na LSF, com exemplos dos processos materiais, mentais e relacionais, retirados do corpus de livros de literatura infantil e juvenil, dentro do projeto "Práticas sociais na contemporaneidade: multiletramentos, identidades e narrativas multimodais". Como suporte teórico-metodológico para a análise de textos produzidos em diferentes mídias e contextos sociais, a LSF pode contribuir para a compreensão da linguagem como prática social multisemiótica em contextos educacionais.

Palavras-chave: Linguística sistêmico-funcional; contexto de situação; metafunções; transitividade. 


\section{ABSTRACT}

Systemic functional Linguistics has contributed to studies in Applied Linguistics and other related areas of study. Thus, in this paper I first present an overview of SFL, the context of situation and the metafunctions, and then I move to the system of transitivity, with examples of material, mental and relational processes, drawn from the corpus of children and teenage picture books from the project entitled 'Social practices in contemporaneity: multiliteracies, identities and multimodal narratives'. As a theoretical and methodological support for the analysis of texts produced in different media and social contexts, SFL can contribute to an understanding of language as a multissemiotic social practice in educational contexts.

Key-words: systemic functional linguistics; context of situation; metafunctions; transitivity.

\section{Introdução}

A linguística sistêmico-funcional (LSF) foi proposta pelo linguista inglês Michael Alexander Kirkwood Halliday, sempre atento a "como de fato usamos a linguagem para construir a realidade e viabilizar relações sociais" (Webster, 2009: 1)1. Trata-se de "uma teoria da linguagem como prática social e também uma metodologia analítica que permite a descrição detalhada e sistemática de padrões linguísticos" (Eggins, 2004: 21). Constitui, pois, ferramenta importante para a análise de textos e gêneros discursivos produzidos em diferentes mídias e contextos sociais. Conforme Barbara e Macedo, a LSF é

caracterizada como uma teoria social porque parte da sociedade e da situação de uso para o estudo da linguagem; seu foco está em

1. Webster (2005) apresenta um breve relato biográfico sobre Halliday, com informações sobre seus estudos referentes à língua chinesa, seu doutorado sob a orientação do linguista J. R. Firth, sua trajetória acadêmica em Cambridge e Edinburgh e sua atuação em reuniões com professores da Educação Básica, atuação esta que o levou a perceber a relação frutífera entre o ensino superior e a Educação Básica. Hasan (2005) também discute a ligação entre contexto e significado proposta por Bronislaw Malinowski, adotada por J. R. Firth e por Halliday. 
entender como se dá a comunicação entre os homens, a relação entre indivíduos e desses com a comunidade. Caracteriza-se também como uma teoria semiótica porque se preocupa com a linguagem em todas as suas manifestações. Procura desvendar como, onde, porque e para que o homem usa a língua, bem como a linguagem em geral, e como a sociedade o faz. (Barbara e Macedo, 2009: 90)

Tendo em vista a contribuição da LSF para a área da Linguística Aplicada principalmente em pesquisas sobre a linguagem em uso, práticas sociais, ensino de línguas e multiletramentos, neste trabalho objetivo focalizar conceitos relevantes da LSF para estudos da linguagem. Assim, inicialmente, apresento um breve relato sobre o projeto "Práticas sociais na contemporaneidade: multiletramentos, identidades e narrativas multimodais" (CNPq, Processo n. 313144/2014-1), para então discutir a abrangência da LSF e os conceitos contexto de situação, metafunções e posteriormente transitividade na LSF, com exemplos retirados do corpus de livros de literatura infantil e juvenil dentro do projeto em tela. Espero que o trabalho possa contribuir para um conhecimento sobre a LSF e possíveis caminhos para o desenvolvimento de compreensão de leitura.

\section{Pesquisando narrativas multimodais contemporâneas em livros de literatura infantil e juvenil}

Em sua visão mais ampla, o projeto (em andamento), inserido na área de Linguística Aplicada, pretende contribuir para uma reflexão acerca da utilização responsável de diferentes recursos semióticos para a produção e interpretação de textos na atualidade. Narrativas (tanto visuais quanto verbais) em livros de literatura infantil e juvenil "constituem um instrumento significativo de socialização, como fonte de mensagens ideológicas sobre o mundo e sobre valores sociais" e têm um papel importante para o desenvolvimento de letramentos e de conhecimentos literários (Painter, Martin e Unsworth, 2013: 1). Nesse sentido, estimular as crianças a entenderem "como essas narrativas são construídas é uma questão educacional importante" (Painter, Martin e Unsworth, 2013: 1). É aí que a LSF pode ser ferramenta útil para que professores e mediadores de leitura possam compreender o funciona- 
mento da linguagem em uso como um sistema da comunicação humana, a estreita ligação entre texto e contexto, as opções verbais e visuais das narrativas, o papel dos agentes, tipos de ações e circunstâncias representadas nas narrativas, a sequência das atividades, a descrição e as falas dos personagens, entre outros aspectos relevantes.

O referido projeto visa analisar narrativas multimodais em três espaços discursivos contemporâneos: narrativas no contexto escolar, produzidas por alunos do Ensino Médio, em videogames e em livros de literatura infantil e juvenil. Cabe salientar que no presente trabalho, os exemplos para ilustrar os conceitos da LSF emergem exclusivamente do corpus das histórias infantis e juvenis, que é composto por mais de 50 obras escritas em português e inglês, devido à área de atuação dos pesquisadores. Essas obras foram selecionadas a partir de critérios estabelecidos por diferentes órgãos institucionais, notadamente pelo PNBE (Programa Nacional Biblioteca da Escola) voltados para as séries iniciais e pela FNLIJ (Fundação Nacional do Livro Infantil e Juvenil). O corpus inclui também alguns livros premiados pelo jornal The New York Times, pelo Prêmio Jabuti, pela Academia de Artes e Ciências Cinematográficas (Oscar) ${ }^{2}$ e outros ${ }^{3}$. Além dessas, outras narrativas com especificações regionais (tais como Lendas amazônicas) ou também de caráter histórico ou geográfico (como A história de Aur e Nia) foram selecionadas.

A LSF vem subsidiando teórica e metodologicamente a análise de questões relacionadas às escolhas léxico-gramaticais, semânticas e contextuais das narrativas do projeto. De acordo com Toolan (1988), por exemplo, uma narrativa sempre estará atrelada a um contexto de cultura (termo utilizado na LSF), ou seja ao cenário sociocultural mais amplo.

2. Os livros Room on the Broom (traduzido para a língua portuguesa como Carona na Vassoura) e The Lost Thing, que fazem parte do corpus, foram adaptados/reconfigurados para versões cinematográficas. Enquanto Room on the Broom recebeu a indicação para o Oscar, The Lost Thing recebeu a premiação de melhor curta-metragem de animação em 2011. Ao longo da pesquisa decidiu-se incluir também filmes de animação, não necessariamente adaptações de livros para filmes. É o caso do filme Bear Story, do diretor chileno Gabriel Osorio, que também recebeu o Oscar de melhor curta-metragem de animação em 2016. 3. Eloísa y los bichos (traduzido para a língua portuguesa como Eloísa e os bichos) também constante do corpus, recebeu prêmio do Banco del Libro da Venezuela e também da Biblioteca Internacional de Jovens (Internationale Jugendbibliothek) de Munique. Disponível em: http://revistababar.com/wp/eloisa-y-los-bichos, acesso em junho de 2017. 
Em relação ao uso da LSF e multimodalidade na interpretação do livro infantil Piggybook com crianças da $6^{\mathrm{a}}$. série do Ensino Fundamental, Williams (2000) aponta que a familiaridade com conceitos básicos da LSF contribuiu para que esses estudantes pudessem identificar padrões de linguagem, tipos de processos e participantes no livro. Segundo Williams (2000: 128), "uma gramática funcional, aliada a uma pedagogia que oriente os alunos a pensarem sobre os efeitos dos padrões linguísticos no significado dos textos pode produzir efeitos positivos para uma análise crítica do discurso".

Além da fundamentação teórica da LSF, a pesquisa também está inserida no domínio teórico e metodológico da abordagem sociossemiótica de multimodalidade e da gramática do design visual (GDV) (Kress \& van Leeuwen, 2001; 2006; Kress, 2010) e estudos de multiletramentos (Unsworth, 2008; 2013; Rojo, 2013; Heberle, 2015), aliados a questões sobre narrativas (Toolan, 1988), livros infantis (Salisbury \& Styles, 2012; Painter, Martin \& Unsworth, 2013) e recursos de Tecnologias Digitais de Informação e Comunicação (TDIC) (Menezes, 2010; Moita Lopes, 2010), entre outros. Esse arcabouço permite a análise criteriosa de recursos semióticos diversos, tais como os elementos visuais, verbais, de movimento, além de outros recursos digitais.

Metodologicamente, cada livro é analisado em relação às opções verbais e visuais, página por página e oração por oração. Verifica-se também a relação entre esses dois tipos de representação. As perguntas de pesquisa que norteiam o trabalho são:

1.Que recursos semióticos são usados nas narrativas multimodais analisadas? Mais especificamente que características léxico-gramaticais, visuais e multimidiáticas podem ser observadas nas narrativas analisadas em livros de literatura infantil e juvenil, nas narrativas interativas e dinâmicas nos vídeo games e nas narrativas dos alunos?

2. Que identidades são manifestadas nessas narrativas e que tipo de paralelo podemos traçar entre os três tipos de narrativa?

3. Como os resultados podem contribuir para o desenvolvimento de multiletramentos? 
A partir dos resultados, pretende-se averiguar a relevância dessas narrativas e dos recursos TDICs em atividades educacionais na escola. A seguir, aponto para estudos de LSF no Brasil.

\section{Abrangência da LSF e estudos no Brasil}

Várias pesquisas que adotam a LSF vem sendo desenvolvidas na Europa, África, Ásia, Oceania e nas Américas em diversas áreas do conhecimento humano, tais como na ciência cognitiva e neurociência, em abordagens computacionais e sistemas adaptativos complexos, estudos culturais, análise do discurso, estudos multilíngues, tradução e interpretação, linguística forense e linguística de corpus, entre outros (Matthiessen, 2009). No Congresso Internacional de LSF (denominado ISFC), em 2015 em Aachen, na Alemanha, por exemplo, a ênfase recaiu em se desafiar as fronteiras do conhecimento, acolher estudos interdisciplinares com a LSF e contribuições advindas da análise crítica do discurso, estudos sobre línguas e suas variações, linguagem literária e não literária, linguagem verbal e outros sistemas semióticos, a perspectiva cognitivista, ou ainda abordagens qualitativas e quantitativas e suas inter-relações com a LSF.

No Brasil, a LSF vem conquistando espaço de destaque nas universidades, graças aos acordos nacionais e internacionais, às diversas publicações e aos esforços de vários pesquisadores, entre os quais a Profa. Leila Barbara, homenageada nesta edição da DELTA. Eventos internacionais de LSF realizados em solo brasileiro incluem: a) o $33^{0}$ Congresso Internacional de Linguística Sistêmico-funcional (na PUC SP, em 2006); b) o $4^{0}$ e o $11^{0}$ congressos da ALSFAL, Associação de Linguística sistêmico-funcional da América Latina, respectivamente na UFSC (em 2008) e na UFSM (em 2015) e c) mais recentemente os eventos do SAL (Systemics Across Languages, https://alsfalsitio. wordpress.com/2017/03/11/encontro-do-projeto-sal/), projeto esse dedicado ao mapeamento sistêmico-funcional de línguas no mundo (Cabral \& Barbara, 2015).

Universidades no Brasil que adotam a LSF como perspectiva teórico-metodológica de estudo da linguagem incluem UFSC, UFSM, 
PUC SP, UFMG, UFLA, UFPB, UFU, UFSJ, PUC-Rio, UERJ, UFPE, UEA, UECE, UFOP, UNICAMP, FURG, UESPi, UFPA, UFRJ, UFRGS, UNIFESP, UFPel, UFT e UnB, entre outras. Já publicações recentes abrangem desde questões de cunho eminentemente teórico até pesquisas relacionadas a ensino de línguas, escrita acadêmica, mídias, gêneros discursivos, avaliatividade ${ }^{4}$, estudos da tradução e multimodalidade. Livros dedicados a LSF incluem os de Barbara e Moyano (2011); Barbara, Rodrigues-Junior e Hoy (2017); Carmo (2014); Fuzer e Cabral (2014); Romero e Ninin (2008) e Vian Jr., Souza e Almeida (2011). Entre artigos em periódicos indexados, destacam-se as edições especiais, como em Heberle e Meurer (2004); Barbara (2009), Motta-Roth e Barbara (2012) e Cabral e Barbara (2015)5. Outros estudos incluem os de Cunha e Souza (2007); Dellagnelo e Meurer (2006); Heberle e Meurer (2006); Lima-Lopes (2005); (Meurer, Bonini e Motta-Roth (2007); Motta-Roth e Nascimento (2009); Meurer e Balocco (2009); Ninin e Barbara (2013); Rottava e Naujorks (2016); Romero e Joseph (2014); Vasconcellos (2009), Vian Jr e Ikeda (2009) e Vian Jr. (2013), entre vários outros.

No grupo de pesquisa NUPDiscurso, sediado no Programa de PósGraduação em Inglês da UFSC e cadastrado no CNPq (onde a pesquisa mencionada está inserida), investigações com fundamentação teórica da LSF incluem, por exemplo, questões de gênero e multimodalidade em propagandas (Almeida 2006; Böelke, 2008), em revistas (Abreu, 2012; Balém, 2015; Lorenset, 2010) e em filmes (Bezerra, 2012; Macedo, 2014; Souza, 2016). Outros estudos do grupo focalizam, por exemplo, apresentações de pesquisa em powerpoint (Nascimento, 2012), artigos

4. A teoria de "avaliatividade" (Appraisal), refere-se a um construto teórico desenvolvido via LSF que investiga os usos de avaliação e atitudes na linguagem verbal, proposto por J. R. Martin (ver Martin e White, 2005. Disponível em: http://www.grammatics. com/appraisal/index.html, acesso em junho de 2017. De acordo com Vian Jr, Souza e Almeida (2011:11), avaliatividade é "um conjunto de significados interpessoais que se debruça sobre os mecanismos de avaliação veiculados pela linguagem, configurados em um sistema que oferece aos usuários possibilidades de utilizar itens avaliativos em suas interações cotidianas".

5. Como se pode observar, a Profa. Dra. Leila Barbara é figura marcante na divulgação de estudos em LSF no Brasil e na América Latina. Dedico este trabalho a ela, pesquisadora entusiasta da linguística sistêmico-funcional, fundadora da ALSFAL, cujos estudos vêm inspirando novos talentos na área. 
acadêmicos eletrônicos (Hendges, 2008) e lendas urbanas (Steffen, 2013).

Após este breve panorama sobre as pesquisas no Brasil, apresento conceitos importantes da LSF, com referência ao corpus selecionado sempre que possível.

\section{Os conceitos "contexto de situação" e "metafunções" (ideacional, interpessoal e textual) ${ }^{6}$}

A teoria proposta por Halliday, que se configura como um construto teórico descritivo e interpretativo da linguagem, como já mencionado, é entendida também como um recurso estratégico para a produção de significados, como representação simbólica de experiências em uma dada cultura e como semiótica social, ou seja, envolvida na construção da experiência social. A descrição linguística é efetuada pelo estudo das escolhas léxico-gramaticais dos textos (considerados instâncias de uso da linguagem) em relação a diferentes níveis ou estratos. Assim, ao considerar a linguagem como um sistema semiótico complexo, Halliday e Matthiessen (2004) referem-se ao princípio da estratificação, como mostra a Figura 1:

Figura 1 - Estratificação (baseado em Halliday \& Matthiessen 2004, In: Meurer, 2006:167).

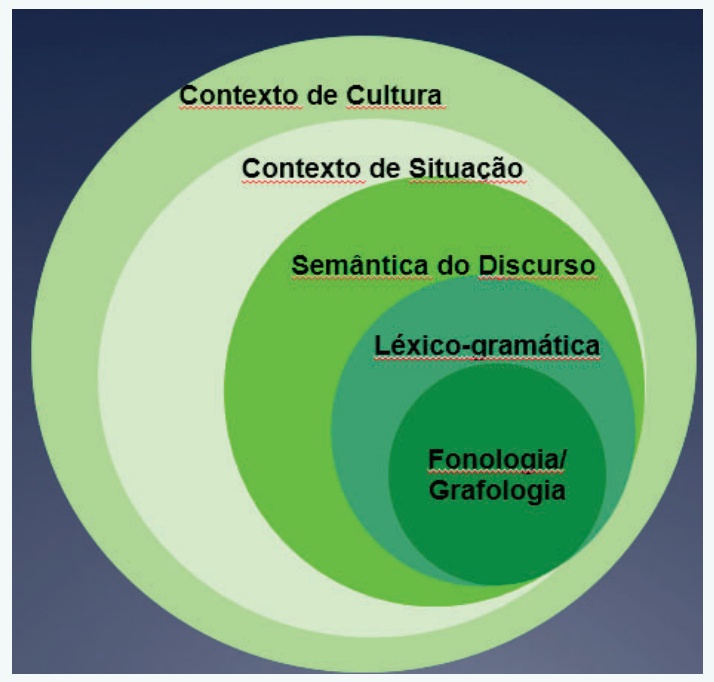

6. Fuzer e Cabral (2014) apresentam mais detalhadamente os conceitos básicos da LSF, bem como as metafunções e os sistemas léxico-gramaticais aplicados à língua portuguesa e também várias atividades com sugestões de resposta. 
A Figura 1 especifica o princípio da estratificação, ou seja, as diferentes "camadas" da linguagem e suas respectivas realizações, partindose de escolhas sistêmicas mais abstratas e abrangentes (contexto de cultura) para as mais concretas e imediatas (escolhas grafológicas e fonológicas). Ao produzirmos um texto, acionamos todos esses níveis ou estratos simultaneamente. Nossas escolhas léxico-gramaticais dependem do contexto. Por exemplo, uma história infantil contada por uma avó descrevendo uma situação de perigo conterá escolhas léxicogramaticais diferentes em comparação a uma situação de perigo relatada por uma vítima numa delegacia de polícia. Semanticamente, também haverá diferenças entre o objetivo das duas narrativas.

Também para ilustrar, pode-se mencionar que o contexto da cultura pode ser reconfigurado ou questionado em relação à questões de gênero mais tradicionais em casos específicos de livros de literatura infantil e juvenil (em seus contextos de situação) e suas opções léxico-gramaticais e visuais em narrativas verbo-visuais como em A pior princesa do mundo, de Anna Kemp, Olívia tem dois papais de Márcia Leite ou ainda Mom and Mum are getting married, de Ken Setterignton. Quando o mediador da leitura ou o professor entende a estreita ligação entre os diferentes estratos, entre texto e contexto, poderá mais eficazmente discutir com as crianças as ações e descrições dos personagens nessas publicações, que fogem dos padrões socioculturais conservadores. Algumas das transgressões no livro de Anna Kemp incluem, por exemplo, o desejo da princesa em não ficar reclusa no castelo, em viajar e conhecer o mundo, como nas orações

Mas príncipe eu quero sair por aí, quero fazer coisas divertidas, me distrair...

Sozinha na torre, a princesa começou a reclamar...

Que flagelo! Ele [o príncipe] me trancou neste estúpido castelo...

Os dois [Soninha e o seu amigo Dragão] rodaram o mundo de ponta a ponta.

Outro exemplo, retirado do livro Olívia tem dois papais, de Márcia Leite, mostra uma criança cujos pais são homossexuais, também observado em Sunderland e McGlashan (2013). Trata-se de uma realidade cada vez mais presente no mundo contemporâneo, como pode ser observado no diálogo entre Olívia e um de seus papais: 
- O Lucas é muito bobo, papai, ele gosta de me provocar, dizendo que eu não tenho mãe...

- Eu falo assim: "Eu não tenho mãe, mas tenho dois pais só pra mim".

- Esta é uma boa resposta, meu bem. Mas sabe, não é todo mundo que acha bom ter dois pais ou duas mães. Cada família é de um jeito. E o Lucas só conhece um tipo de família - o pai explicou.

Pela análise dos diferentes contextos de situação e de cultura e das escolhas semânticas e léxico-gramaticais, outros valores e questões sociais relevantes podem ser observados nas narrativas, tais como solidariedade (em Carona na Vassoura), relacionamento com estranhos (em Eloísa e os bichos) ou resolução de conflitos (em Da guerra do mares e das areias).

O Quadro 1 abaixo apresenta mais especificamente a relação entre o contexto, a semântica e a léxico-gramática:

Quadro 1 - Contexto de situação, semântica e léxico-gramática (Halliday e Hasan, 1985; Halliday, 1978; Ventola, 1988, in Heberle, 2000: 297)

\begin{tabular}{|c|c|c|}
\hline CONTEXTO SITUACIONAL & SEMÂNTICA & LÉXICO-GRAMÁTICA \\
\hline Traço do contexto & Função da Linguagem & (nível: oração) \\
\hline $\begin{array}{c}\text { estruturas semióticas } \\
\text { da situação }\end{array}$ & $\begin{array}{c}\text { componentes funcionais } \\
\text { da semântica }\end{array}$ & escolhas léxico-gramaticais \\
\hline Campo do discurso & Significados ideacionais & Estruturas de transitividade \\
\hline $\begin{array}{l}\text { (o que está acontecendo) } \\
\text { a presente atividade social } \\
\end{array}$ & conteúdo ideacional & oração como representação \\
\hline Relações interpessoais & Significados interpessoais & Estruturas de modo \\
\hline (quem participa) & interação pessoal & $\begin{array}{c}\text { oração como troca de } \\
\text { experiência }\end{array}$ \\
\hline \multicolumn{3}{|l|}{$\begin{array}{l}\text { a relacão entre os participantes } \\
\text { envolvidos }\end{array}$} \\
\hline Modo do discurso & Significados textuais & $\begin{array}{c}\text { Estruturas temáticas e } \\
\text { coesão }\end{array}$ \\
\hline $\begin{array}{l}\text { (o papel da linguagem) } \\
\text { canal simbólico ou retórico }\end{array}$ & estrutura textual & oração como mensagem \\
\hline
\end{tabular}

Através do Quadro 1, vemos que o contexto de situação é formado por três componentes: campo, relações e modo. Na estratificação se- 
mântica, temos as metafunções equivalentes: ideacional, interpessoal e textual, que são instanciadas na léxico-gramática respectivamente pelas estruturas de transitividade, de modo e temáticas. A variável campo especifica a atividade, o que está acontecendo. A variável Relações, por sua vez, refere-se ao maior ou menor poder e envolvimento afetivo entre os interlocutores, assim como contato mais frequente ou ocasional. Já Modo diz respeito ao papel da linguagem e ao canal de comunicação. Ainda em relação ao Quadro 1, vê-se que a unidade básica para a análise léxico-gramatical é a oração. O sistema de transitividade, como dito acima, é a materialização léxico-gramatical do componente ideacional; modo e modalidade, do componente interpessoal; e tema e rema, do componente textual.

A seguir, para exemplificar o contexto de situação ${ }^{7}$, eis as variáveis campo, relações e modo, em relação à leitura de um livro de literatura infantil, efetuada conjuntamente entre uma avó e seu neto.

Quadro 2 - Exemplo de um contexto de situação

Campo - leitura do livro infantil Carona na Vassoura, escrito por Julia Donaldson e Axel Scheffler e tradução de Gilda de Aquino. A leitura é efetuada por uma avó e seu neto, que se encontram no quarto do menino, antes de dormir. Os dois alternam a leitura em voz alta e comentam sobre a história e as ilustrações do livro;

Relações - Dois participantes, a avó, de idade madura (leitora mais experiente) e seu neto de seis anos (leitor menos experiente), numa relação afetiva muito próxima, sem distância social. A vó ajuda o neto quando há alguma dificuldade de compreensão. Há, pois, solidariedade entre os dois.

Modo - Canal fônico, gráfico e visual: processo dialógico. Meio: falado e escrito. Papel da linguagem: constitutivo ${ }^{8}$.

Em estreita ligação com o contexto de situação, encontram-se as metafunções. Trata-se de um princípio importante da teoria da LSF, referente ao fato de a organização gramatical das línguas naturais

7. Discussões sobre o contexto de situação podem ser observadas, por exemplo, em Motta-Roth e Heberle (2007).

8. Um exemplo do papel da linguagem verbal/escrita como auxiliar e não constitutivo pode ser observado na narrativa visual Bárbaro, que não contém linguagem verbal na narrativa em si, somente no título e informações fora da narrativa em si (ver a análise deste livro em Heberle e Constanty, 2016). 
possibilitar a realização de três funções da linguagem, três tipos de significado presentes em qualquer uso da linguagem. Qualquer texto, pois, é uma composição polifônica multifuncional (Halliday, 1978), porque envolve as metafunções ideacional, interpessoal e textual. Vejamos o que nos diz Thompson sobre essas três funções:

1. Usamos a linguagem para falar sobre nossas experiências do mundo, incluindo os mundos de nossas mentes, para descrever eventos, estados e entidades envolvidas nessas experiências (a função denominada ideacional).

2. Também utilizamos a linguagem para interagir com outras pessoas, para estabelecer e manter relações sociais com elas, influenciar seu comportamento, expressar nossos pontos-de-vista e solicitar ou modificar os pontosde-vista de outros (a função interpessoal).

3. Finalmente, ao usarmos a linguagem organizamos nossas mensagens para indicar como elas se enquadram a outras mensagens e com o contexto mais amplo no qual estamos falando ou escrevendo (a função textual).

(Thompson, 2004: 28)

Em outras palavras, a função ideacional representa a construção de experiências, estados ou eventos no mundo, e a função interpessoal representa as relações sociais entre os participantes na comunicação. Essas duas funções adquirem significado e são organizadas através da função textual, que é internamente coerente e inerente ao contexto. Em relação a textos multimodais, como livros de literatura infantil, a partir da gramática visual de Kress e van Leeuwen (2006), as metafunções ideacional, interpessoal e textual são denominadas respectivamente representacional, interativa e composicional, mas não serão abordadas neste trabalho.

Ao se analisar a função ideacional, verifica-se os aspectos léxicogramaticais referentes ao conteúdo das mensagens, aos fenômenos do mundo, à realidade relatada. $\mathrm{O}$ sistema de transitividade, como veremos adiante, é a realização léxico-gramatical da função ideacional ${ }^{9}$. Já a análise da função interpessoal refere-se às opções léxico-gramaticais das atitudes e juízos, da participação e envolvimento dos participantes no evento discursivo, das relações estabelecidas com os outros, através

9. A função ideacional ainda dispõe do significado lógico onde são realizados os complexos oracionais através do sistema lógico-semântico e de interdependência (Halliday e Matthiessen, 2004). Neste artigo não focalizo este tipo de significado. 
das estruturas de modo (modo indicativo: orações declarativas e interrogativas, modo imperativo e também modalidade). A função textual, por sua vez, refere-se aos recursos gramaticais que operacionalizam a mensagem, que organizam as escolhas linguísticas como mensagem, através das estruturas temáticas. É através da função textual que as metafunções ideacional e interpessoal são organizadas e ganham textura. Essas funções ocorrem simultaneamente, mas como analistas do discurso e estudiosos da linguagem, nossa análise é descrita linearmente, para então estabelecermos as ligações com os outros níveis.

A investigação de significados interpessoais numa narrativa infantil, por exemplo, possibilita a discussão das relações entre os personagens e deles com a jovem leitora. No caso do livro Olívia tem dois papais, há vários diálogos entre a Olívia e seus dois pais: em termos léxico-gramaticais, o uso de discurso direto com perguntas e respostas dos personagens em orações declarativas e interrogativas simula as vozes dos personagens, como se a leitora mirim estivesse ouvindo a fala deles. Esses significados interpessoais sugerem proximidade e afetividade entre os personagens, ao mesmo tempo em que também contribuem para estabelecer uma relação estreita entre a narrativa e a criança leitora. Além disso, os diálogos permitem que questões sociais nem sempre aceitas em diferentes contextos socioculturais possam ser abordadas de maneira informal, naturalizada.

\section{Transitividade na teoria sistêmico-funcional}

A experiência humana é geralmente entendida como um fluxo de eventos ou acontecimentos, atos ligados a agir, dizer, sentir, ser e ter. $\mathrm{O}$ sistema léxico-gramatical da transitividade é responsável pela materialização desses atos, que constrói a experiência humana num conjunto de tipos de processos (verbos), com cada tipo modelando uma fatia da realidade, ou seja, um setor de como representamos a nossa experiência de mundo (abstrato, físico e da consciência). Conforme já apontado anteriormente, o sistema de transitividade segundo Halliday configura-se como a base teórica para a análise da metafunção ideacional (do estrato semântico) e da variável campo, no contexto de situação (ver Quadro 1). Verifica-se o papel da experiência na gramática, determinando-se quem 
faz o quê a quem em que circunstâncias. Há três componentes básicos para a análise de transitividade:

a) um processo, ou seja um tipo de verbo (grupo verbal)

b) os participantes envolvidos no processo (grupo nominal)

c) as circunstâncias ligadas ao processo (grupo adverbial)

No corpus analisado, o livro Rapunzel e o Quibungo, adaptado por Cristina Agostinho e Ronaldo Simões Coelho, refere-se à história infantil de uma menina muito bonita na Bahia que cantava lindas canções. Com sete anos, ela é capturada pelo monstro Quibungo e presa numa torre de bambu numa castanheira muito alta. Anos mais tarde, o príncipe Dakarai escuta aquela linda voz e observa o que acontece. Finalmente, o Quibungo é derrotado e Rapunzel e Dakarai ficam juntos perto de seu povo. Exemplos de grupos nominais, verbais e adverbais dessa história incluem

\begin{tabular}{|l|l|l|}
\hline Nasceu & uma linda menininha & com cabelos muito compridos \\
\hline Grupo verbal & Grupo nominal & Grupo adverbial \\
\hline
\end{tabular}

\begin{tabular}{|l|l|l|l|}
\hline O monstro & ficou (maravilhado) & e zás! raptou & a menininha. \\
\hline Grupo Nominal & Grupo verbal & Grupo verbal & Grupo nominal \\
\hline
\end{tabular}

\begin{tabular}{|l|l|l|}
\hline Prendeu & a menininha & em uma torre de bambu. \\
\hline Grupo verbal & Grupo nominal & Grupo adverbial \\
\hline
\end{tabular}

\begin{tabular}{|l|l|l|}
\hline Após tantos anos & Rapunzel & cantou uma canção \\
\hline Grupo adverbial & Grupo nominal & Grupo verbal \\
\hline
\end{tabular}

Pelo sistema de transitividade, existem seis tipos de processos (verbos): material, mental, relacional, comportamental, verbal e existencial. Uma das distinções básicas dos tipos de processos refere-se às experiências do mundo externo (processos materiais) e aquelas do mundo interior, da consciência (processos mentais). Os processos relacionais, por sua vez, servem tipicamente para classificar, generalizar e identificar aspectos das experiências que vivenciamos. Esses são os três principais tipos de processos do sistema de transitividade, sobre os quais dedico uma breve atenção. Já os processos comportamentais, 
referentes a comportamentos psicológicos e manifestações fisiológicas, inserem-se na fronteira entre os materiais e mentais. Na fronteira entre os processos relacionais e materiais estão os processos existenciais, aqueles que denotam existência. Os processos verbais, por sua vez, encontram-se entre os processos mentais e relacionais.

A partir de uma concepção topológica, o sistema de transitividade, representado na Figura 2, apresenta os tipos de processos como um espaço semiótico, com fronteiras contínuas, não rígidas, e as categorias principais representam tipos prototípicos dos processos (Halliday \& Matthiessen, 2014:216)

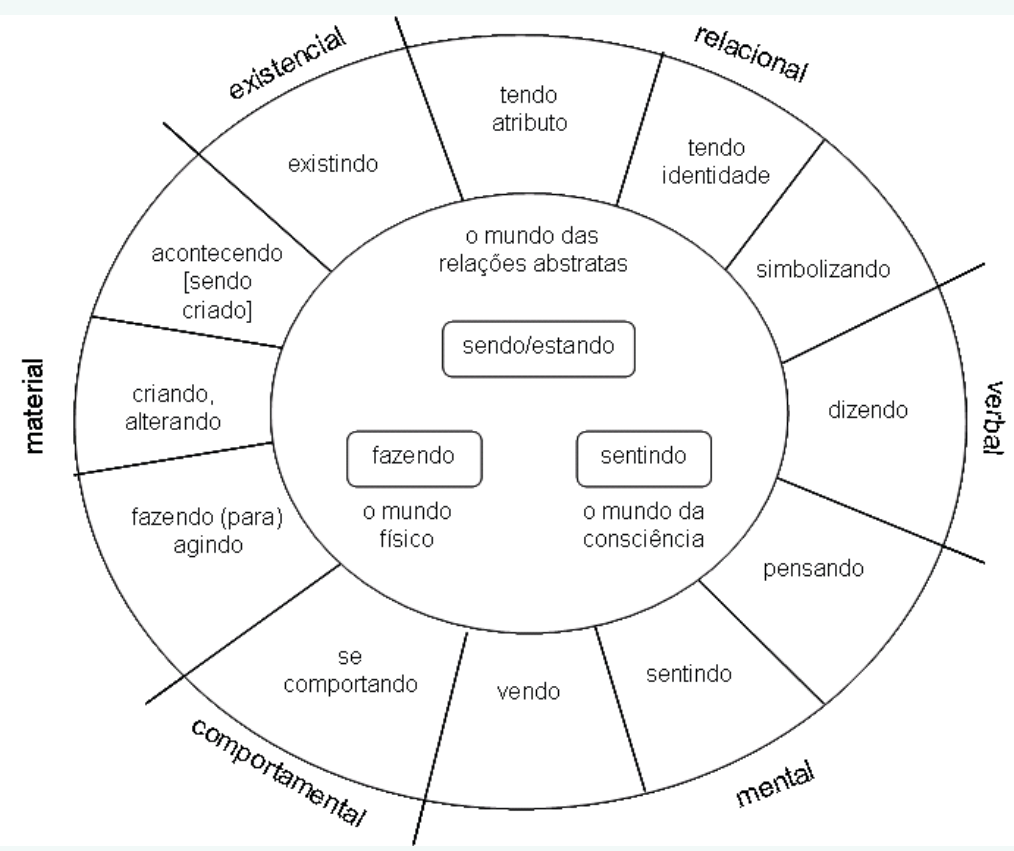

Figura 2 - A gramática da experiência: tipos de processo em português (com base em Halliday \& Matthiessen, 2004: 172 e Halliday e Matthiessen, 2014: 216, também em Cunha e Souza, 2007: 55)

Por esta representação topológica dos tipos de processos (Figura 2), vê-se que as demarcações não delimitam fronteiras; ao contrário, estabelecem uma configuração contínua onde as significações se mesclam para estabelecer as principais formas de representação de realidade dentro de uma dimensão triádica: sendo/estando, fazendo e sentindo. 
Pode-se também caracterizar a transitividade como uma rede de sistema, através de uma concepção tipológica, como mostra a Figura 3:

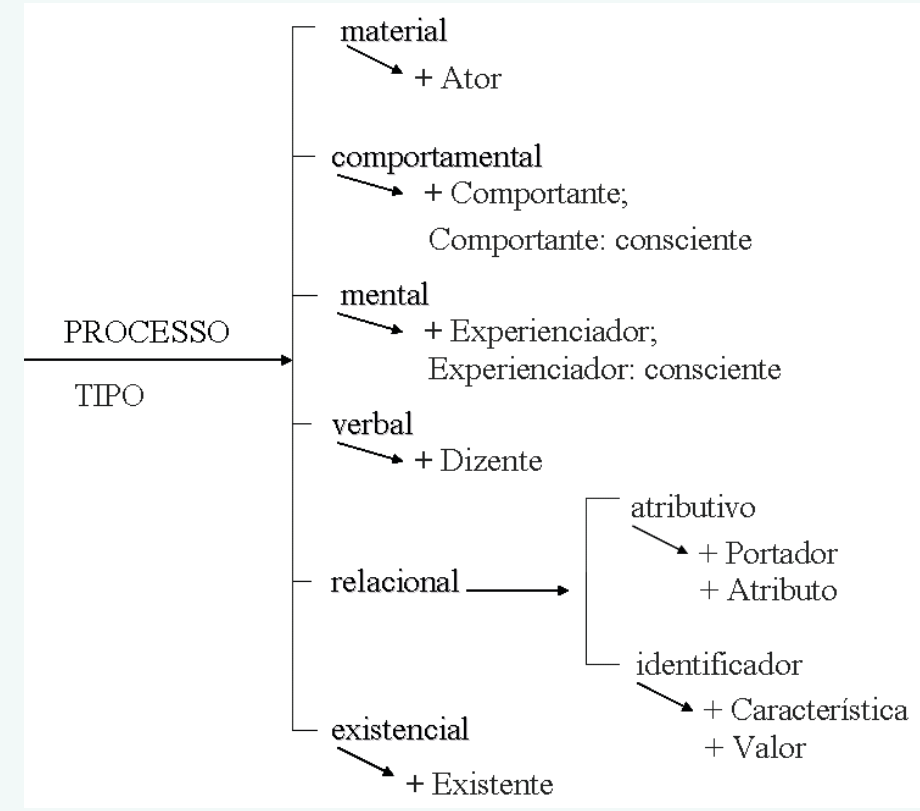

Figura 3 - TRANSITIVIDADE representada como rede de sistemas (Halliday \& Matthiessen, 2004: 173; Halliday e Matthiessen, 2014: 219).

A Figura 3 apresenta o espaço semiótico representado como uma rede sistêmica, contendo os seis tipos de processo que temos a nosso dispor para a representação do mundo físico, da consciência e de relações abstratas. O nível de exploração limita-se nessa figura apenas aos processos e seus principais participantes, não sendo explorado os subtipos de cada processo e seus participantes adjacentes (Gonzaga, 2011).

Apresento exemplos dos diferentes tipos de processos, retirados da narrativa $A$ Lenda da Vitória Régia (Mello, 2011), uma das oito lendas amazônicas constantes do corpus. A narrativa conta a história da bela índia Naimã que se apaixona por um guerreiro de uma tribo vizinha. Ela coloca uma flor rosa em seus cabelos para conquistá-lo. Eles conversam muito, ele vai embora, mas promete que retornará. 
Naimã espera muito tempo por ele, sem sucesso. Uma índia da tribo mente para Naimã que ele tinha partido para se encontrar com a Deusa Lua. Naimã vê o reflexo da lua nas águas, pula para encontrá-lo, mas se afoga. O Deus Tupã, com pena dela, cria uma planta semelhante à flor rosa. Trata-se de uma lenda de esperança e amor, mas também de traição, ligada à planta amazônica vitória-régia.

Quadro 3 - Exemplos de processos e participantes no sistema de transitividade na LSF

\begin{tabular}{|c|c|}
\hline Tipos de processos & $\begin{array}{l}\text { Exemplo } \\
\text { (Processos em negrito com participantes sublinhados) }\end{array}$ \\
\hline material & $\begin{array}{l}{[\underline{\text { Naimã }]} \text { colocou uma enorme flor rosada nos cabelos e }} \\
\text { aproximou-se dele. } \\
\text { Porém o tempo passou e o guerreiro não retornou no } \\
\text { período previsto. } \\
\text { O Deus Tupã...criou uma planta semelhante à flor rósea. }\end{array}$ \\
\hline comportamental & Eles conversaram durante uma noite inteira* \\
\hline mental & [Naimã] gostava de se pintar \\
\hline verbal & $\begin{array}{l}\text { Num certo dia, outra cunhatã da tribo... disse, para enganar } \\
\text { Naimã, que ele havia partido para o encontro da Deusa Lua. }\end{array}$ \\
\hline relacional & $\begin{array}{l}\text { Naimã era uma índia muito bonita. } \\
\text { Tinha uma vida normal na aldeia. }\end{array}$ \\
\hline existencial & $\begin{array}{l}\text { Há muitos anos ... existia uma comunidade de mulheres } \\
\text { guerreiras, exímias caçadoras...(A Lenda do Muiraquitã) }\end{array}$ \\
\hline
\end{tabular}

*Aqui conversar se refere a bater papo. Note-se que os processos comportamentais podem estar próximos dos verbais como neste caso, mas muitas vezes também estão perto dos processos mentais.

Acredito que atividades de operacionalização do sistema de transitividade com os leitores iniciantes poderão despertá-los para uma compreensão de aspectos contextuais mais amplos e também mais específicos das narrativas, especialmente quando eles têm a oportunidade de identificar e distinguir os diferentes processos, os participantes e as circunstâncias das narrativas.

Dedico-me, a seguir, à discussão dos três principais processos e seus participantes correspondentes, a saber, processos materiais, mentais e relacionais. 


\section{Processos materiais}

Os processos materiais, os mais numerosos e diversificados entre os tipos de processos, designam ações físicas e eventos ou acontecimentos, tais como nas seguintes orações, retiradas da história Rapunzel e o Quibungo ${ }^{10}$ :
...nasceu uma linda menininha com cabelos muito compridos O tempo passava e seus cabelos continuavam crescendo Ela foi brincar na beira da Lagoa do Abaeté [o monstro] raptou a menininha [o monstro] Prendeu a menina em uma torre de bambu Os pais de Rapunzel procuraram por ela durante um tempão [Dakarai] ia todos os dias até lá Nesse momento, uma linda moça apareceu na janela Mais que depressa Dakarai subiu.

Nessa narrativa, os processos materiais contribuem para o desenrolar da narrativa, com ações dramáticas tais como prender ou raptar e/ou mostrar mudanças no fluxo dos acontecimentos (ir brincar, aparecer). Os leitores mirins poderiam, por exemplo, identificar os processos, os principais personagens e o papel de cada um na história. As circunstâncias também ajudam a criar o caráter dramático da narrativa, por exemplo, numa torre de bambu no alto de uma castanheira ou indicando o tempo (durante um tempão, nesse momento) ou frequência (todos os dias).

Os participantes dos processos materiais são denominados Ator (quem realiza o processo) e Meta (quem ou o quê é afetado pelo processo). Nas orações acima, da narrativa da Rapunzel, os Atores incluem uma linda menininha, os pais de Rapunzel, Dakarai, o monstro. Metas incluem a menininha e a menina.

Entre os participantes de processos materiais, há também o Beneficiário, referente à entidade que é beneficiada pela ação, tais como (em itálico) "[O Rei Floresbongo] comprou dois vestidos farfalhosos e maravilhíssimos para elas", do livro Amarílis (Furnari, 2013). Há também o participante Escopo, o participante não afetado pelo pro- 
cesso, como um prolongamento do processo, quando o processo é lexicalmente vazio. Por exemplo, [Olívia] fez uma pose diferente com as pernas, do livro Olívia tem dois papais.

Outros exemplos do corpus, com os processos materiais (em negrito) incluem:

As guerreiras protegiam a região com ajuda dos índios Guacaris, que moravam nas proximidades e, junto com as Amazonas, guardavam as pedras verdes. - A Lenda do Muiraquitã (Mello, 2011)

...uma linda moça apareceu na janela. Amarrou seus cabelos na ponta de um cipó, e as longas tranças deslizaram até o chão. - Rapunzel e o Quibungo (Agostinho e Coelho, 2012)

Os mares viviam em guerra com as areias... Milênios passaram... Ninguém ganhava nada. Ninguém perdia nada. - Da guerra dos mares e das areias (Veludo, 2013)

Halliday e Mathiessen (2004: 187-189) explicam que os processos materiais transitivos e intransitivos podem também ser classificados em dois tipos principais: a) criativos (exemplos do corpus: surgir, acontecer, realizar, construir, abrir e pintar) ou b) transformativos, que modificam a Meta, de alguma forma (derrotar, transformar, $m u$ dar, cortar, destruir, devorar, exemplos do corpus). Nos processos criativos, o Ator ou a Meta passa a existir devido ao processo. Já no processo transformativo, o Ator ou a Meta já existente sofre algum tipo de transformação. Para ilustrar, utilizo trechos do corpus:

As mulheres prepararam oferendas para dar de presente a elas. (Processo material criativo) - A Lenda da Mãe D'Água (Mello, 2011)

Uma vez por ano as índias guerreiras realizavam uma festa dedicada à lua... (Processo material criativo) - A Lenda do Muiraquitã (Mello, 2011)

[Quibungo] preferiu cortar as tranças da menina com os dentes. (Processo material: transformativo) - Rapunzel e o Quibungo (Agostinho e Coelho, 2012)

Num artigo [como o presente texto], não há como discutir todos os aspectos referentes aos processos, sub-processos, participantes e circunstâncias do sistema de transitividade de Halliday e Mathiessen 
(2014), os quais dedicam 147 páginas para esse importante tema ${ }^{11}$. Cabe salientar que os processos materiais são característicos de livros infantis e importantes para se perceber os cenários, as aventuras, ações e acontecimentos, bem como os agentes, os personagens responsáveis pelas ações (os participantes) e as circunstâncias atreladas às ações (de tempo, localização, modo ou causa, por exemplo).

Passaremos agora à apresentação de outro tipo de verbo, denominado processo mental, que diz respeito a ações das nossas mentes, e não a atividades materiais.

\section{Processos mentais}

Os processos mentais dizem respeito às experiências do mundo de nossa consciência, de emoção (gostar, apreciar, temer), cognição (considerar, supor, saber, compreender), percepção (perceber, notar) ou desejo (querer, desejar, planejar). Esses processos envolvem dois participantes, sendo um participante humano ou antropomorfizado (como por exemplo, as montanhas não sabiam se ficavam todas juntas), aquele que tem uma mente: é o ser que pensa, percebe ou sente, denominado Experienciador, que é sempre necessário. O segundo participante é denominado Fenômeno, aquilo que é sentido, percebido ou desejado. Em comparação com processos materiais, os processos mentais se caracterizam por sua versatilidade, pois o participante Fenômeno pode representar não somente uma pessoa, um animal, objeto concreto, uma substância ou abstração, como também orações (que representam fatos ou atos) ${ }^{12}$. Já o Experienciador, ao contrário do Ator, restringe-se a um ser com consciência.

11. Os processos materiais podem ainda, por exemplo, ser classificados como intencionais ou involuntários e não representar necessariamente eventos físicos concretos (Halliday e Matthiessen, 2004). Alguns exemplos deste tipo de processos materiais (retirados de outro corpus (http://www1.folha.uol.com.br/folha/dinheiro/, acesso em nov. 2006) incluem: a) Ações da Petrobrás podem despencar, alerta analista. b) Fundos reduzem taxas de administração. E c) Produção de veículos cai em novembro.

100

12. Exemplos de fato (sublinhado): $\mathrm{O}$ fato de eu não ter sido entendido me irritou. Exemplo de ato (sublinhado): Eu vi o trem partir. 
Vejamos exemplos de processos mentais, retirados do corpus:

No caminho, Pedro, o Confuso, pensava: Não sei por que me casei com Constança. Dom Afonso foi quem quis....Pedro amava Inês. - Inês (Mello e Massarani, 2015)

[Rapunzel] nem se lembrou das ameaças do monstro. Rapunzel se esqueceu de tirar o colar que ganhou de presente de Dakarai.) - Rapunzel e o Quibungo (Agostinho e Coelho, 2012)

Por estes trechos, pode-se perceber que os processos mentais (em negrito) saber, resolver, decidir, pensar, querer, amar, lembrar e esquecer diferenciam-se dos processos materiais, discutidos anteriormente. Os Experienciadores desses processos estão envolvidos em emoções e atividades de cognição. No caso das histórias infantis, a análise desse tipo de verbo pode contribuir para que professor e alunos possam perceber essas diferentes experiências cognitivas e emocionais e serve também "para construir o fluxo de consciência do falante/escritor" (Fuzer e Cabral, 2014: 54). Alguns exemplos de processos mentais referentes às quatro categorias - percepção, cognição, desejo e emoção - incluem (lista baseada em Halliday e Matthiessen, 2004: 210) ${ }^{13}$ :

\begin{tabular}{|l|l|}
\hline Percepção & perceber, notar, ouvir, ver, sentir \\
\hline Cognição & $\begin{array}{l}\text { saber, convencer, surpreender, lembrar, compreender, } \\
\text { considerar, apreciar, imaginar, fingir, hipotetizar, duvidar, } \\
\text { esquecer, }\end{array}$ \\
\hline Desejo & $\begin{array}{l}\text { querer, desejar, esperar (por algo), pretender, determinar, recusar, } \\
\text { concordar, decidir, planejar, almejar }\end{array}$ \\
\hline Emoção & $\begin{array}{l}\text { gostar, adorar, amar, detestar, odiar, exultar, arrepender-se, } \\
\text { deplorar, cobiçar, entusiasmar-se, atrair, ofender, alegrar, } \\
\text { entristecer, encorajar, interessar, preocupar, contentar, chocar, } \\
\text { confortar, fascinar, doer, assustar, amedrontar }\end{array}$ \\
\hline
\end{tabular}

De acordo com Halliday e Mattiessen (2004: 2014), essas quatro categorias, assim como todos os outros sistemas de experiência, são indeterminadas e as fronteiras entre elas não são rígidas.

Os processos mentais podem ser considerados uma estratégia argumentativa eficaz, ligada ao "apelo a emoções" ou argumentum ad populum. $\mathrm{O}$ argumento ad populum constitui-se numa técnica de argu-

13. Fuzer e Cabral (2014:58) também apresentam uma lista com tipos de processos mentais, além de materiais (p. 48-49) e outros. 
mentação baseada na capacidade do protagonista da argumentação, o Experienciador dos processos mentais, de despertar emoções no público alvo. Este tipo de argumento é entendido como uma tentativa de utilização de uma técnica persuasiva com base emotiva a fim de provocar entusiasmo, aprovação e desejos em um determinado público (Heberle, 1999), como na narrativa Da guerra dos mares e das areias:

As montanhas não sabiam se ficavam todas juntas ou espalhadas pelos continentes, os lagos não tinham resolvido se seriam de água doce ou salgada. ...E os rios não tinham decidido se desceriam as montanhas. - Da guerra dos mares e das areias (Veludo, 2013).

Ou na narrativa da Olívia

Ela sabia exatamente como usar algumas palavras para conseguir as coisas que queria.

[Olívia] gostava de ficar sozinha, ali no escuro. Sentia um medo gostoso. Todo mundo gosta de dia feliz, ela concluiu.

Olívia adorava esse cheiro (de tinta fresca e terebintina) - Olívia tem dois papais (Leite, 2010)

Já em estudos de multiletramentos, pode-se investigar que escolhas léxico-gramaticais e visuais são utilizadas numa história infantil para expressar diferentes sentimentos, ligados à percepção, cognição, desejo ou emoção.

\section{Processos relacionais}

Processos relacionais estabelecem relações entre duas entidades e "as orações relacionais são comumente usadas para representar seres no mundo em termos de suas características e identidades" (Fuzer e Cabral: 65). Existem três tipos de situações nas orações que contêm processos relacionais: intensivas, atributivas e circunstanciais, que, por sua vez, podem ser Atributivas ou Identificativas.

Para exemplificar, eis exemplos do corpus:

Flosgo era um velho muito velho...

E o fogo era gigantesco (Exemplos de Processo relacional atributivo)

- Amarilis (Furnari, 2013) 
Outros exemplos de processos relacionais incluem:

Tom é meu irmão, estou ao seu lado desde que nasci. (Processo relacional identificativo intensivo + Processo relacional circunstancial) - Tom (Neves, 2012)

Nós [Soninha e o Dragão] somos um time campeão... (Processo relacional atributivo intensivo)

Você é a pior princesa do mundo. (Processo relacional atributivo intensivo)

O príncipe todo emburrado estava de volta. (Processo relacional circunstancial) - A pior princesa do mundo

Processos relacionais, que contribuem para se identificar, caracterizar, qualificar pessoas, objetos ou situações e podem também atribuir pertencimento a determinados grupos sociais e posse, são muito utilizados em histórias infantis. A observação desse tipo de processo pode auxiliar os jovens leitores a descrever os personagens, suas identidades, suas caraterísticas e principais relações estabelecidas entre eles.

Nesta seção apresentei os principais processos da LSF: materiais, mentais e relacionais. Naturalmente os outros três tipos (verbal, existencial e comportamental) também mereceriam destaque. Porém, como já antecipado, minha atenção recaiu nos três primeiros, por restrições de espaço.

Para finalizar esta seção, parece-me que a exploração de textos como as narrativas nos livros de literatura infantil e juvenil via LSF pode contribuir para uma sensibilização de alunos às possibilidades da língua e à variações de estilo, além de outras questões já mencionadas. Em consonância com Mamo (2016:85), acredito que

ao se sentirem confiantes em sua habilidade para interagir com qualquer texto e em sua sensibilidade quanto à linguagem, os alunos podem se tornar menos intimidados pelas diferentes nuances de significado e mais dispostos a explorar um texto por si próprios, mesmo que não entendam tudo. Isto é um argumento forte para o empoderamento e autonomia do aluno ${ }^{14}$.

14. Minha tradução de: Once they are confident in their own ability to engage with any text and can trust their sensitivity to language, they will be less daunted by the possibility of different nuances of meaning and more keen to explore a text on their own, even if 


\section{Considerações finais}

Em sua perspectiva mais ampla, como já apontado, a LSF constitui tanto "uma teoria sobre a língua como processo social quanto uma metodologia analítica para a descrição de padrões linguísticos" (Vian Jr, 2013: 127). Neste trabalho procurei apresentar um breve panorama sobre a LSF e suas possibilidades de interação com outras áreas do saber humano, enfatizando que, como aparato teórico-metodológico, a LSF permite a investigação de textos de diferentes práticas sociais em seus respectivos contextos. Conforme tentei enfatizar, a LSF oferece subsídios importantes para o estudo da linguagem como semiótica social, levando em conta o contexto de cultura, o contexto de situação, a semântica do discurso, a léxico-gramática, até as unidades grafológicas e fonológicas. A fim de exemplificar os principais processos no sistema de transitividade, eu trouxe exemplos retirados de livros de literatura infantil juvenil, de minha pesquisa sobre práticas sociais, identidade e narrativas multimodais. Por restrições de espaço, focalizei somente os três principais processos do sistema de transitividade. A investigação sobre que tipos de processos, participantes e circunstâncias são realizados e quais deles predominam num texto pode contribuir para se identificar estratégias argumentativas e perspectivas ideológicas e conscientizar leitores sobre a estreita relação existente entre o uso da gramática e o respectivo contexto de situação.

Em relação às perguntas de pesquisa, no presente estágio de desenvolvimento do estudo, percebe-se que nas narrativas dos livros infantis os processos materiais são os mais frequentes, mas os outros cinco tipos de processo também são usados. Esses livros, como narrativas multimodais, estão sendo analisados em termos de significados verbais e visuais e a LSF vem contribuindo para a investigação das identidades, das emoções e características dos personagens, o desenrolar das narrativas, os detalhes sobre quem faz o quê em que circunstâncias. Ao se descrever os personagens, por exemplo, os processos relacionais são fundamentais. E os processos mentais contribuem para veicular emoções, pensamentos e desejos. Quanto à análise de videogames 
(tópico não apresentado neste trabalho), em consonância com a LSF que enfatiza a estreita ligação entre texto e contexto, resultados como o de Silva (2016) mostram que a localização de jogos exige que se considere especificações culturais referentes aos países onde são jogados. Nessas narrativas, há também uma incidência alta de processos materiais, mas os outros tipos de processo também são utilizados.

Quanto aos resultados parciais da pesquisa e sua contribuição para o desenvolvimento de multiletramentos, pode-se afirmar que nossa pesquisa também considera outros recursos semióticos utilizados, além dos aspectos verbais, para a verificação de quais significados são expressos em linguagem verbal, quais em linguagem visual, quais em cenas de filmes, a exemplo do trabalho de Unsworth (2013), que analisa o livro e o filme de The Lost Thing nas versões impressa e fílmica. Como narrativas multimodais, os livros são analisados em relação aos significados visuais e interativos com o apoio do construto teórico-metodológico da GDV, inspirada na LSF, e de estudos de multimodalidade e multiletramentos, que extrapolam a análise de aspectos verbais somente para incluir outros sistemas semióticos, tais como os significados produzidos em vídeos, livros interativos e outros disponíveis na Internet (Kress e van Leeuwen, 2006; Kress, 2010; Kalantzis, Cope, Chan e Dalley-Trim, 2016; Rojo e Moura, 2012). Recursos semióticos adicionais diretamente ligados à leitura das narrativas incluem jogos, textos (impressos ou digitais), atividades, brinquedos e demais acessórios que acompanham os livros.

Para finalizar, saliento que estudos em LSF (tais como o de Christie, 2005) enfatizam a atuação do professor para planejar atividades pedagógicas significativas direcionadas aos estudantes, criar oportunidades para se falar sobre os textos, verificar os padrões da linguagem dos textos estudados, explorar os modos como esses padrões constroem os significados e oportunizar o desenvolvimento de habilidades interpretativas e críticas de análise do texto (Christie, 2005:91).

Recebido em: 05/02/2017

Aprovado em: 30/08/2017

E-mail: viviane.heberle@ufsc.br 


\section{Referências bibliográficas}

ABReu, Bruna. B. 2012. Eleven things that girls love: a systemic functional and critical discourse analysis of the representation of femininity in the comic book Turma da Mônica Jovem. Dissert. Mestrado. Programa de Pós-Graduação em Inglês/UFSC.

AlmeIDA, Danielle B. L. 2006. Icons of Contemporary Childhood: A Visual and Lexicogrammatical Investigation of Toy Advertisements. Tese de doutorado. Programa de Pós-Graduação em Inglês, UFSC.

BALEN, Maria Gabriela S. da S.. 2015. A multimodal analysis of love/ dating texts of two teenage girls' magazines websites: todateen and Seventeen. Dissert. Mestrado. Programa de Pós-Graduação em Inglês/ UFSC.

Barbara, Leila (org.) 2009. Delta. Vol 25, n. 3. Tópicos de Linguística Sistêmico- Funcional na América Latina.

Barbara, Leila \& Celia M. Macedo. 2009. Linguística SistêmicoFuncional para a Análise de Discurso: um Panorama Introdutório. Cadernos de Linguagem e Sociedade, v. 10, p. 89-107.

BARBARA, Leila; Moyano, Estela. 2011. Textos e Linguagem acadêmica: explorações sistêmico-funcionais em espanhol e português. Campinas e Buenos Aires: Mercado de letras e UNGS.

Barbara, Leila; Adair Rodrigues-JúnIor. S. \& Hoy, G. M. V. (orgs.). 2017. Estudos e pesquisas em Linguística Sistêmico-Funcional. São Paulo: Mercado de Letras.

Belmiro, Celia A. 2010. A multimodalidade na literatura infantil e a formação de professores leitores. Revista Brasileira de Linguística Aplicada, Belo Horizonte, v. 10, n. 2, p. 403-420. (Disponível em http://www.scielo.br/pdf/rbla/v10n2/07.pdf)

Bezerra, Fábio A. S. 2012. Language and image in the film Sex and the City: a multimodal investigation of the representation of women. Tese de doutorado. Programa de Pós-Graduação em Inglês, UFSC.

BöHLKE, Rossana de Felippe. 2008. Título: Constructing ideal body appearance for women: a multimodal analysis of a tv advertisement. Tese de doutorado. Programa de Pós-Graduação em Inglês, UFSC.

CABral, Sara Regina S. \& Leila BARBARA, L (orgs.) 2015. Letras, UFSM, v. 25, n. 50, p. 7-12, jan./jun. (Disponível em https://periodicos.ufsm. br/letras/article/view/20201)

CARMO, Claudio M. 2014. O lugar da cultura nas teorias de base sistêmicofuncional: multimodalidade e produção de sentido na dança-ritual de Oxóssi. Curitiba: Appris. 
ChristiE, Francis. 2005. Language education in the primary years. Sydney: UNSW Press.

CunHA, Maria Angélica. F. \& Maria Medianeira Souza. 2007. Transitividade e seus contextos de uso. Rio de Janeiro: Lucerna.

Dellagnelo, Adriana K. \& José Luiz Meurer. 2006. Echoes from teacher discourse: An inside-out perspective. Ilha do Desterro, Florianópolis, v. 50, p. 155-174. (Disponível em https://periodicos.ufsc.br/index. $\mathrm{php} /$ desterro/article/view/7273)

EGGINS, Suzanne. 2004. An Introduction to Systemic Functional Linguistics. London: Continuum.

Fuzer, Cristiane \& Sara R. S. CABral. 2014. Introdução à gramática sistêmico-funcional em língua portuguesa. Campinas: Mercado de Letras.

GonZAGA, Jair João. 2011. Intricate cases in clauses in SFG concerning the grammar of Brazilian Portuguese. Tese de doutorado. Programa de Pós-Graduação em Inglês, UFSC.

Halliday, Michael A. K. 1978. Language as Social Semiotic. London: Edward Arnold.

Halliday, Michael A.K. \& Ruqaiya Hasan. 1985. Language, context, and text: aspects of language in a social-semiotic perspective. Oxford: Oxford University Press.

Halliday, Michael A. K. \& Chrstian Mathiessen. 2004. An introduction to functional grammar. $3^{\text {rd }}$. ed. London/New York: Arnold.

2014. Halliday's introduction to functional grammar. $4^{\text {th }} \mathrm{ed}$. London and New York: Routledge.

HaSAn, Ruqaiya. 2005. Language and society in a systemic functional perspective. In: Ruqaiya Hasan; Christian Matthiessen \& Jonathan Webster. Orgs. Continuing discourse on language: a functional perspective. Nova York: Continuum Intern. Publishing Group, p.55-80.

HeberLe, Viviane M. 1999. Two kinds of argument in editorials of women's magazines. In: Proceedings of the Fourth International Conference of the International Society for the Study of Argumentation. Amsterdam: SIC SAT, v. 1. p. 322-327.

2000. Análise crítica do discurso e estudos de gênero: subsídios para a leitura e interpretação de textos. In: Mailce B. M. Fortkamp \& Lêda Tomitch. Orgs. Aspectos da Linguística Aplicada: Estudos em Homenagem ao Prof Hilário Inácio Bohn. Florianópolis: Insular, p. 289-316.

.2015. Estudos em multiletramentos e possíveis intersecções com o ensino de inglês no Brasil. In: Mailce Mota; Anelise Corseuil; Magali 
S. Beck \& Celso Tumolo. Orgs. Língua e Literatura na Época da Tecnologia. Florianópolis: EDUFSC, p. 277-290.

Heberle, Viviane \& José Luiz Meurer. (orgs.) 2004. Systemic-functional linguistics in action. Ilha do Desterro (UFSC), Florianópolis, v. 46, p. 13-17, 2004. Disponível em https://periodicos.ufsc.br/index.php/ desterro/issue/view/648.

2006. Formação de professores de línguas estrangeiras: considerações a partir da linguística aplicada, linguística sistêmicofuncional e análise crítica do discurso. In: Sheila E. Oliveira \& Josalba F. Santos. Orgs. Mosaico de linguagens, Campinas; Pontes, p. 91-98.

Heberle, Viviane \& Verônica Constanty. 2016. Meaning without words: analyzing the picture book Bárbaro through a social semiotic perspective. Letras, Santa Maria, v. 26, n. 52, p. 89-109, jan./jun. (Disponível em https://periodicos.ufsm.br/letras/article/ view/25325/14663)

Hendges, Graciela R. 2008. Tackling genre classification: the case of HTML research articles. Tese de doutorado. Programa de PósGraduação em Inglês, UFSC.

Kalantzis, Mary; Bill Cope; Eveline Chan \& Leanne Dalley-Trim. Literacies. $2^{\text {nd }}$ ed. 2016. Melbourne: Cambridge University Press.

Kress, Gunther. 2010. Multimodality: A Social Semiotic Approach to Contemporary Communication. London: Routledge.

KRESS. Gunther \& Theo van LeEuwen. 2001. Multimodal discourse-The modes and media of contemporary communication.Londo: Edward Arnold.

2006. 2nd.edition. Reading images: The grammar of visual design. London: Routledge.

Lima-LoPes, Rodrigo E. 2005. Avaliação de um sistema de marcação textual aplicado à gramática sistêmico-funcional. In: Tony B. Sardinha. Org. A Língua Portuguesa no Computador. São Paulo: Mercado de Letras, p. 220-235.

LoRenset, Caroline C. 2010. Visual and lexicogrammatical analysis of websites of women's magazines. Dissert Mestrado. Programa de Pós-Graduação em Inglês, UFSC.

MACEDO, Litiane B. 2014. Hollywood romantic comedies: a social semiotic analysis of the leading female characters in It Happened One Night and The Proposal. Dissert Mestrado. Programa de Pós-Graduação em Inglês, UFSC.

MAмо, Rebekka. 2016. Literature in the ELT classroom: "No way, José!" or "Oh yes, s'il vous plait!"? In: Daniel Xerri \& Odette Vassallo 
Orgs. Creativity in English language teaching. Floriana, Malta: ELT Council, p. 77-86.

Martin, James \& Peter R.R. White. 2005. The Language of Evaluation. London: Palgrave.

Matthiessen, Christian. 2009. Ideas and new directions. In: Michael A.K. Halliday \& Jonathan Webster. Orgs. Continuum companion to systemic functional linguistics. London/New York: Continuum, p. $12-58$.

Menezes, V. Narrativas multimídia de aprendizagem de língua inglesa. Rev. Signos, 43, Número Especial. Monográfico No 1, p. 183-203. Valparaíso, 2010. (Disponível em: http://www.scielo.cl/pdf/signos/ $\mathrm{v} 43 \mathrm{~s} 1 / \mathrm{a} 11)$.

Meurer, José Luiz \& Anna Elizabeth Balocco. 2009. A linguística sistêmico-funcional no Brasil: interfaces, agenda e desafios. Anais do SILEL. Vol. 1. Uberlândia: EDUFU. (Disponível em http://www. ileel.ufu.br/anaisdosilel/pt/arquivos/gt_lg14_artigo_8.pdf).

Meurer, José Luiz; Adair Bonini \& Desirée MotTA-Roth (orgs.). Gêneros: teorias, métodos, debates. $2^{\mathrm{a}}$. ed. São Paulo: Parábola, 2007.

Meurer, José Luiz. 2006. Integrando estudos de gêneros textuais ao contexto de cultura. In: Acir M. Karwoski; Beatriz Gaydeczka \& Karim S. Brito. Orgs. Gêneros textuais: reflexões e ensino. 2a. ed. revista e aumentada. Rio de Janeiro: Lucerna.

Moita Lopes, Luiz Paulo. 2010. Os novos letramentos digitais como lugares de construção de ativismo político sobre sexualidade e gênero. Trab. Linguística Aplicada., Dez, vol.49, no.2, p.393-417.

Motтa-Roth, Desirée \& Fábio S. Nascimento. 2009. Transitivity in visual grammar: concepts and applications. Linguagem \& Ensino (UCPel) (Disponível em http://coralx.ufsm.br/desireemroth/algumas publicacoes/linguagem_ensino_nascimento.pdf)

Motta-Roth, Desirée \& Leila Barbara. (orgs.). 2012. Revista D.E.L.T.A. Documentação de Estudos em Linguística Teórica e Aplicada, Número Especial sobre Systemic Functional Linguistics. 28. ed. São Paulo: LAEL/PUCSP. (Disponível em https://revistas.pucsp.br/index. $\mathrm{php} / \mathrm{delta} /$ issue/view/121)

Motta-Roth, Desirée \& Viviane M. Heberle. 2007. O conceito de "estrutura potencial do gênero" de Ruqayia Hasan. In: José Luiz Meurer; Adair Bonini \& Desirée Motta-Roth, D. Orgs. Gêneros: teorias, métodos, debates. 2ed. São Paulo: Parábola Editorial, p. $12-28$

2015. A short cartography of genre studies in Brazil. Journal of English for Academic Purposes, v. 19, p. 22-31. 
Nascimento, Roseli G. 2012. Research genres and multiliteracies: Channelling the audience's gaze in powerpoint presentations. Tese de doutorado.

Ninin, Maria \& Leila Barbara. 2013. Engajamento na perspectiva linguística sistêmico-funcional em trabalhos de conclusão de curso de Letras. Trabalhos em Linguística Aplicada. Campinas: Unicamp/ IEL, v. 52, n. 1, p. 127-146.

Painter, Clare; J R Martin \& Len Unsworth. 2013. Reading Visual Narratives: Image Analysis of Children's Picture Books. Londres: Equinox.

Rojo, Roxane H. R. (org). 2013. Escol@ conectada: Os multiletramentos e as TICs. São Paulo, SP: Parábola.

Rojo, Roxane H. R. \& Eduardo Moura. (orgs.). 2012. Multiletramentos na Escola. São Paulo, SP: Parábola.

Romero, Tania Regina \& Maria Otilia G Ninin. (orgs.). 2008. Linguística Sistêmico-Funcional como Instrumento na Educação. São Carlos: Pedro \& João Editores, 2008.

Romero, Tania. Regina S. \& Norma. L. L. JosePh, 2014. Padrões Tipológicos da Função Interpessoal Modalidade em Artigos Científicos de Ciências Agrárias: Diferenças e Similitudes entre Português e Inglês. DELTA. Documentação de Estudos em Linguística Teórica e Aplicada (PUCSP. Impresso), v. 30.1, p. 115-136.

Rottava, Lúcia \& Jane da Costa Naujorks (orgs.) 2016. Linguística sistêmico-funcional: interlocuções da formação docente e ensino. 1. ed. Porto Alegre: Instituto de Letras UFRGS.

Salisbury, Martin \& Morag STyles, M. 2012. Children's picturebooks: the art of visual storytelling. London: Laurence King.

SiLVA, Fernando. 2016. The mapping of localized content in the videogame Infamous 2: a multimodal corpus-based analysis. Tese de doutorado. Programa de Pós-Graduação em Estudos da Tradução, UFSC.

SouzA, Anderson A. 2008. Do the right, be firm, be fair': A systemic functional investigation of national anthems written in English. Tese de doutorado. Programa de Pós-Graduação em Inglês, UFSC.

SouzA, Felipe Antônio. 2016. Don't mess with a witch: power relations, gender and subcultural issues on witches' representation in the media. Dissert. Mestrado. Programa de Pós-Graduação em Inglês/UFSC.

StefFen, Giana T. 2013. Legends in liquid modernity: a critical discourse analysis of contemporary urban legends. Tese de doutorado. Programa de Pós-Graduação em Inglês, UFSC. 
Sunderland, Jane \& Mark McGlashan. 2013. Looking at picturebook covers multimodally: the case of two-Mum and two-Dad picturebooks. Visual Communication v. 12(4): 473-496.

THOMPson, Geoff. 2004. Introducing functional grammar. $2^{\text {nd }}$ ed. London: Taylor \& Francis Ltd.

Toolan, Michael. 1988. Narrative: a critical linguistic introduction. New York: Routledge.

UnSWORTH, Len. (Ed). 2008. Multimodal Semiotics: functional analysis in contexts of education. London, New York: Continuum.

. 2013. Re-configuring image-language relations and interpretive possibilities in picture books as animated movies: A site for developing multimodal literacy pedagogy. Ilha do Desterro, vol 64, pp 15-48 (Disponível em https://periodicos.ufsc.br/index.php/desterro/article/ view/2175-8026.2013n64p15/25078

Vasconcellos, Maria Lúcia. B. 2009. Systemic Functional Translation Studies (SFTS): The theory travelling in Brazilian environments. DELTA. Documentação de Estudos em Linguística Teórica e Aplicada (PUCSP. Impresso), v. 25, p. 585-607. (Disponível em https://revistas. pucsp.br/index.php/delta/article/view/28265).

Ventola, Eija. 1988. Text analysis in operation: a multilevel approach In: Robin P. Fawcett \& David J. Young (eds). New Developments in Systemic Linguistics. Theory and Application, vol 2. London: Frances Pinter.

VIAN JR, Orlando. 2013. Linguística sistêmico-funcional, linguística aplicada e linguística educacional. In: Luiz Paulo Moita Lopes. Org. Linguística Aplicada na modernidade recente - Festschrift para Antonieta Celani .São Paulo: Parábola, p. 123-141.

VIAN JR., Orlando \& Sumiko N. IKEDA. 2009. O ensino gênero resenha pela abordagem sistêmico-funcional na formação de professores. Linguagem \& Ensino, 12/1: 13-32. Rio Grande do Sul/Pelotas.

Vian JR., Orlando; Anderson A. Souza \& Fabíola S. D. P. Almeida (orgs.). 2011. A linguagem da avaliação em língua portuguesa. Estudos sistêmico-funcionais com base no Sistema de Avaliatividade. São Carlos: Pedro \& João Ed.

WeBsTER, Jonathan. 2005. Introduction. In: Ruqaiya Hasan; Christian Matthiessen \& Jonathan Webster. Orgs. Continuing discourse on language: a functional perspective. New York: Continuum Intern. Publishing Group, p 3-13.

WiLliams, Geoffrey. 2000. Children's literature, children and uses of language description. In: Len Unsworth. Org. Researching language in schools and communities. London: Cassell, p. 111-129. 


\section{Livros infantis mencionados no artigo}

Agostinho, Cristina \& Ronaldo S. Coelho. 2012. Adaptação. Rapunzel e o Quibungo. Belo Horizonte: Mazza Produções.

Buitrago, Jairo. 2013. Eloísa e os bichos. Trad. Marcia Leite. São Paulo: Pulo do Gato.

Cartelle, Castor. 2012. A história de Aur e Nial Cartelle e Lor. Belo Horizonte: Ed. da PUC Minas.

Donaldson, Julia \& Axel Scheffler. 2012. Carona na vassoura. Tradução: Gilda Aquino. São Paulo: Brinque-book.

FurnARI, Eva. 2013. Amarílis. São Paulo: Moderna.

Kemp, Anna. 2013. A pior princesa do mundo. São Paulo: Paz e Terra.

LeITE, Márcia. 2010. Olivia tem dois papais. São Paulo: Companhia das Letrinhas.

MelLo, Nazaré. 2011. Lendas amazônicas para crianças. Belém: Prefeitura de Belém.

Mello, Roger \& Mariana Massarani. 2015. Inês. São Paulo: Companhia das Letrinhas.

Moriconi, Renato. 2013. Bárbaro. São Paulo: Companhia das Letrinhas.

Neves, André. 2012. Tom. Porto Alegre: Editora Projeto.

Setterington, K. 2004. Mom and Mum Are Getting Married! Toronto: Second Story Press.

TAN, Shaun. 2000. The Lost Thing. Sydney: Hachette.

Veludo, Pedro. 2013. Da guerra dos mares e das areias: Fábula sobre as marés. São Paulo: Quatro Cantos. 